Macedonian Pharmaceutical Bulletin, 66 (Suppl 1) 19 - 20 (2020)

Online ISSN $1857-8969$

UDC: 616.1-02:615.277.065(497.6)

DOI: 10.33320/maced.pharm.bull.2020.66.03.009

Short communication

\title{
Cardiovascular toxicity of antineoplastic medicines in Bosnia and Herzegovina
}

\author{
Biljana Tubić ${ }^{1,2}$ \\ ${ }^{1}$ Agency for medicines and medical devices of Bosnia and Herzegovina, Veljka Mlađenovića bb, \\ 78000 Banjaluka, Bosnia and Herzegovina \\ ${ }^{2}$ Faculty of Medicine - Department of Pharmacy, University of Banjaluka, Save Mrkalja 14, 78000 Banjaluka, \\ Republic of Srpska - Bosnia and Herzegovina
}

\section{Introduction}

Cancer and heart diseases are the leading causes of morbidity and mortality in many countries worldwide. Using chemotherapy and targeted therapies has led to an improvement in cancer survival rates and, unfortunately, higher cardiac adverse side effects - cardiotoxicity (Leong et al., 2019). Antineoplastic medicines have improved overall survival and progression-free survival to the oncological patients (Jemal et al., 2011; Varricchi et al., 2019). Mentioned medicines can be associated with several side effects, including cardiovascular toxicity. The National Cancer Institute defines cardiotoxicity in very general terms as "toxicity that affects the heart" (www.cancer.gov/dictionary/). Cardiotoxicity can develop in a subacute, acute, or chronic manner (Albini et al., 2018). Mitochondria are central targets for antineoplastic medicineinduced cardiovascular toxicity (Varricchi et al., 2019).

Antineoplastic-related cardiovascular toxicities have been presented in many countries especially North American and European (Leong et al., 2019). Reported results from western countries are showed that the incidence rate of cancer treatment-induced cardiotoxicity is related with several chemotherapy and targeted therapies: anthracycline $(0.9 \%-57 \%)$, cyclophosphamide (2\%-28\%), trastuzumab (0\%$28 \%$ ) and bevacizumab (1.7\%-10.9\%) (Leong et al., 2019).

The Agency for medicines and medical devices of Bosnia and Herzegovina (ALMBIH) was established by the Law on Drugs and Medical Devices ("Official Gazette of B\&H, No. 58/08") as an authorized body for medicines and medical devices produced and used in B\&H. In 2019. ALMBIH has become full member of Uppsala Monitoring Centre - World Health Organization.

The aim of this work was to investigate the cardiovascular toxicity of antineoplastic medicines in Bosnia and Herzegovina.

\section{Materials and methods}

Data extraction and analysis

All individual case suspected reports (ICSRs) which were received by the ALMBIH for the period 2011-2019 were used as data source. The ICSRs were entered into Microsoft ExcelTM tables (Microsoft Corporation, Redmond, WA, USA). The number, characteristics, and sources of ICSR, suspected drugs, adverse drug reactions (ADRs), and patient characteristics were analyzed quantitatively. The first level of Anatomical Therapeutic Chemical (ATC) classification was used to characterize

*b.tubic@almbih.gov.ba 
suspected drugs in ICSR. ADRs were coded according to the Medical Dictionary for Regulatory Activities System Organ Class (SOC) classification.

\section{Results and discussion}

In Bosnia and Herzegovina, the highest number of received spontaneous adverse drug reactions is related with follow groups of ATC classification: group Antiinfectives for systemic use (referred as group J) (24.8\%), and group Various (referred as group V) (24.8\%). Behind of these groups, on the second place is group Antineoplastic and immunomodulating agents (referred as group L with $22.8 \%)$.

Based on the data from ICSRs in Bosnia and Herzegovina cardiovascular toxicities are avoided using medicines for malignancies (40\%), and for cardiovascular diseases (20\%). Cardiotoxicity was mainly manifested in patients aged 45-64 years $(60 \%)$. It was reported equally in men and women. The most common reactions (MedDRA) were: Tachycardia (40\%), Arrhythmia (20\%), Bradycardia (20\%) and Acute coronary syndrome (20\%). The top ten suspected International Nonproprietary Names (INNs) were: Bcg vaccine (21.4\%), Cytarabine (16.1\%), Etoposide (10.7\%), Oxaliplatin (8.9\%), Rituximab (7.1\%), Temozolomide (5.4\%), Infliximab (5.4\%), Vemurafenib (5.4\%), Leuprorelin (3.6\%) and Paclitaxel (3.6\%).

Abnormal heart rhythm had the highestincidence among all types of cardiovascular toxicity of antineoplastic medicines in Bosnia and Herzegovina.
Presented results are similar to previously published results (Leong et al., 2019). It is necessary to find the new biomarkers to identify patients at a high risk for the development of these complications is a high priority. Guidelines for cancer treatment that take cardiologic conditions into account are currently lacking and need to be developed (Albini et al., 2018).

\section{Conclusion}

Cardiovascular toxicity of antineoplastic medicines in Bosnia and Herzegovina is one of the most adverse effects arising from cancer therapeutics and a major barrier to survivorship.

\section{References}

Albini, A., Pennesi, G., Donatelli, F., Cammarota, R., De Flora, S., Noonan, D.M., 2010. Cardiotoxicity of anticancer drugs: the need for cardiooncology and cardio-oncological prevention. J. Natl. Cancer Inst. $102,14-25$.

Jemal, A., Bray, F., Center, M.M., Ferlay, J., Ward, E., Forman, D., 2011. Global cancer statistics. CA Cancer J. Clin. 61, 69-90.

Leonga, S.L., Chaiyakunapruka, N., Leea, S.W.H., 2019. Antineoplastic-related cardiovascular toxicity: A systematic review and meta-analysis in Asia. Crit. Rev. Oncol. Hematol. 141, 95-101.

Van der Geer, J., Hanraads, J.A.J., Lupton, R.A., 2000. The art of writing a scientific article. J. Sci. Commun. $163,51-59$.

Varricchi, G., Ameri, P., Cadeddu, Ch., Ghigo, A., Madonna, R., Marone, G., Mercurio, V., Monte, I., Novo, G., Parrella, P., Pirozzi, F., Pecoraro, A., Spallarossa, P., Zito, C., Mercuro, G., Pagliaro, P., Tocchetti, C.G., 2018. Antineoplastic drug-induced cardiotoxicity: a redox perspective. front. Physiol. 9, 167. 